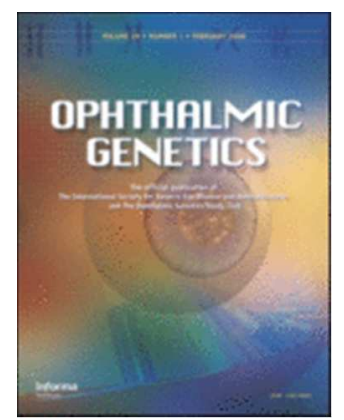

\title{
A recurrent splice-site mutation in EPHA2 causing congenital posterior nuclear cataract
}

\begin{tabular}{|r|l|}
\hline Journal: & Ophthalmic Genetics \\
\hline Manuscript ID & NOPG-2017-0092.R2 \\
\hline Manuscript Type: & Case Report \\
\hline Date Submitted by the Author: & n/a \\
\hline Complete List of Authors: & $\begin{array}{l}\text { Berry, Vanita; UCL, Institute of Ophthalmology, Genetics } \\
\text { Pontikos, Nikolas; UCL Genetics Institute } \\
\text { Albarca-Aguilera, Monica; Saphetor.com } \\
\text { Plagnol, Vincent; UCL Genetics Institute } \\
\text { Massouras, Andreas; Saphetor.com } \\
\text { Prescott, DeQuincy; UCL, Institute of Ophthalmology } \\
\text { Moore, Anthony; University of California, San Francisco } \\
\text { Arno, Gavin; Moorfields Eye Hospital \& UCL Institute of Ophthalmology } \\
\text { Cheetham, Michael; UCL, Institute of Ophthalmology } \\
\text { Michaelides, Michel; UCL, Institute of Ophthalmolgy, Genetics; Moorfields } \\
\text { Eye Hospital }\end{array}$ \\
\hline Keywords: & \begin{tabular}{l} 
EPHA2, Congenital Cataract, WGS \\
\hline
\end{tabular} \\
\hline
\end{tabular}




\section{A recurrent splice-site mutation in EPHA2 causing congenital posterior nuclear cataract}

Vanita Berry ${ }^{1 *}$, Nikolas Pontikos ${ }^{1,3 \$}$, Monica Albarca-Aguilera ${ }^{4}$, Vincent Plagnol ${ }^{3}$, Andreas Massouras ${ }^{4}$, DeQuincy Prescott ${ }^{1}$, Anthony T. Moore ${ }^{5}$, Gavin Arno ${ }^{1}$, Michael E. Cheetham ${ }^{1}$ and Michel Michaelides ${ }^{1,2^{*}}$

\$ These authors contributed equally to this work.

${ }^{1} \mathrm{UCL}$ Institute of Ophthalmology, 11-43 Bath Street, London EC1V 9EL, UK;

${ }^{2}$ Moorfields Eye Hospital, London EC1V 2PD, UK;

${ }^{3}$ UCL Genetics Institute, London WC1E 6BT, UK;

${ }^{4}$ Saphetor.com;

${ }^{5}$ UCSF, USA;

Corresponding authors:

Dr Vanita Berry, Department of Genetics, Institute of Ophthalmology, University College London, 11-43 Bath Street, London EC1V 9EL, UK; Phone: +44 207608 4041 FAX: +44 207608 6863; email: v.berry@ucl.ac.uk

Professor Michel Michaelides, Department of Genetics, Institute of Ophthalmology, University College London, 11-43 Bath Street, London EC1V 9EL, UK; Phone: +44 207608 6864, FAX: +44 207608 6903; email: michel.michaelides@ucl.ac.uk 
$\underline{\text { Abstract }}$

Intoduction: Inherited cataract, opacification of the lens, is the most common worldwide cause of blindness in children. We aimed to identify the genetic cause of autosomal dominant posterior nuclear cataract in a four generation British family.

Methods: Whole genome sequence (WGS) was performed on two affected and one unaffected individual of the family and further validated by direct sequencing. Haplotype analysis was performed via genotying.

Results: A splice-site mutation c.2826-9G>A in the gene EPHA2, encoding EPH receptor $A 2$ was identified and found to co-segregate with disease.

Conclusions: We have identified a recurrent splice-site mutation c.2826-9G>A in EPHA2 causing isolated posterior nuclear cataract, providing evidence of further phenotypic heterogeneity associated with this variant.

KEYWORDS: Congenital cataract, EPHA2, Whole genome sequencing

\section{Introduction}

Cataract is the most common cause of blindness in the world, representing almost half of all causes of blindness globally: the WHO estimates that 18 million people are bilaterally blind from cataract (1). The incidence of congenital cataract in the UK is 1$15 / 10,000$ births; this is a significant cause of childhood visual impairment $(2,3)$. Congenital cataract alone and/or the associated surgical treatment can lead to irreversible amblyopia, glaucoma and retinal detachment.

Congenital cataract can occur in isolation or in association with other systemic abnormalities, and is a predominant feature in more than 200 genetic disorders. However, the majority (about one-third) of congenital cataracts are familial and display substantial genotypic and phenotypic heterogeneity $(4,5)$. Inheritance is most commonly autosomal dominant (AD), usually with complete penetrance but with highly variable expressivity. Less frequently, autosomal recessive and X-linked 
inheritance patterns are seen. The phenotypic classification is based on the position and type of the lens opacity including: anterior polar, posterior polar, nuclear, lamellar, coralliform, blue-dot (cerulean), cortical, pulverulent, polymorphic, complete cataract and posterior nuclear cataract $(6,7)$.

Significant progress has been made in identifying the molecular genetic basis of human cataract. Multiple genes $(>38)$ have been implicated including those coding for crystallins (CRYAA, CRYAB, CRYBA1, CRYBA4, CRYBB1,CRYBB2, $C R Y B B 3, C R Y G C, C R Y G D$ and $C R Y G S$ ), membrane gap junction proteins (GJA3, GJA8), water channel proteins (AQP0), solute carrier protein (SLC16A12), various cytoskeletal proteins (e.g., phakinin, filensin, vimentin), transmembrane proteins (TMEM114), lens intrinsic membrane protein (LIM2), chromatin modifying protein-4B (CHMP-4B), transcription factor genes (PAX6, FOXE3, EYA1, MAF, PITX3) (8), an endoplasmic reticulum membrane-embedded protein, Wolframin (WFS1) (9), and receptor tyrosine kinase gene EPH receptor A2 (EPHA2) (10).

Here we report a recurrent mutation in the EPHA2 gene causing an isolated autosomal dominant posterior nuclear cataract in a four generation British family.

\section{Methods}

Phenotyping: The family in this study was identified through the proband attending the Genetic Service at Moorfields Eye Hospital, London, UK. Local ethics committee approval was obtained and all individuals taking part gave written informed consent. All the family members underwent full ophthalmic examination, with careful slit lamp examination. In this pedigree, all affected individuals were diagnosed as having posterior nuclear cataract.

DNA Extraction: Genomic DNA was extracted from EDTA sequestered blood samples taken with informed consent and local ethical approval using the Nucleon II DNA extraction kit (Scotlab Bioscience, Strathclyde, Scotland, UK). 
Whole Genome Sequencing (WGS): Genomic DNA was processed using the Illumina TruSeq DNA PCR-Free Sample Preparation kit (Illumina) and sequenced using an Illumina Hiseq 2500, generating mean genome coverage of 35x. WGS was done by a service provider (Macrogen.Inc., Korea). Raw data in fastq format was analysed using Saphetor's online-bioinformatics platform (https://portal.saphetor.com). Sequence reads were aligned to UCSC hg19 human reference sequence (build GRCh37) and variants were called using Saphetor's variant discovery pipeline. The variants identified in the three analysed samples were analysed together using joint genotyping. A total of 402,106 heterozygous mutations segregated in the two affected individuals while being absent from the unaffected individual. After filtering for novel mutations, not seen in Kaviar (http://db.systemsbiology.net/kaviar/) or in the Gnomad databases (http://gnomad.broadinstitute.org), 14,265 variants remained. Only coding variants or non-coding variants within 50 base pairs into an intron were kept, reducing the variant list down to 344 . Finally, this list was further filtered using a gene panel of 117 genes linked to congenital cataract which yielded a single variant. The congenital cataract gene list was created by merging genes associated to congenital cataract by three different sources: HPO January 2017 version (http://human-phenotype-ontology.github.io/), Centogen (https://www.centogene.com/centogene/centogene-test-catalogue detail.php?test=NGS\&ID=3d960353\&search=Panel\&disease=Cataract panel) and CatMap (http://cat-map.wustl.edu/).

Sanger sequencing: In order to validate the variant identified by next-generation sequencing, bi-directional direct Sanger sequencing was performed in all the individuals. Genomic DNA was amplified by PCR using GoTaq 2X master mix (AB gene; Thermo Scientific, Epsom, UK) and EPHA2-specific primers using the primer3 program (Table 1). PCR conditions were as follow: $94 \mathrm{C}$ for 10 minutes followed by 30 cycles of amplification of 30 seconds at $94^{\circ} \mathrm{C}, 30$ seconds at $60^{\circ} \mathrm{C}$, and 45 seconds at $72^{\circ} \mathrm{C}$. The final step was disabled. Direct Sanger sequencing of PCR products was performed using the BigDye version 3.1 (Applied Biosystems) on a ABI 3730 DNA Analyzer and analyzed using sequence analysis version 5.2. After confirming the variant, segregation analysis was performed in all the individuals in the family. We also screened 200 healthy individuals from the European population for the identified variant. Furthermore, 96 isolated patients were screened from our 
autosomal dominant congenital cataract (ADCC) panel for EPHA2 by bi-directional direct Sanger sequencing of all coding exons and intron/exon boundaries.

Haplotype Analysis: Haplotype analysis was performed, in this family carrying the splice mutation c.2826-9G>A, to compare with the previously published families harbouring the same mutation as in our study. Five microsatellite markers from the 1p36.1 region namely D1S2697, D1S436, D1S1592, D1S2826 and D1S2644 were used to check the haplotype in the pedigree. PCR-based genotyping was performed using qPCR Master mix and fluorescent ABI marker set HD-10 version 2.5 (Applied Biosystems, Warrington, UK) for the chromosome 1p region encompassing EPHA2 gene. PCR products were mixed with HD-400 size standard and were separated on ABI PRISM 3730 Genetic Analyzer (Applied Biosystems). Genotypes were assigned with GeneMarker software V1.85 (Applied Biosystems). The region was refined using markers from Marshfield, GDB Human genome database and Ensemble databases.

\section{Results}

A large four-generation pedigree comprising 15 members, including 8 affected individuals, 5 unaffected individuals, and 2 spouses were examined and all affected members had evidence of posterior nuclear cataract (PNC). Opacities were seen in the embryonic and fetal nucleus along with the posterior pole of the lens. All affected individuals had bilateral congenital cataract and age at onset was from birth; one patient (IV-4) shown in the pedigree also had glaucoma (Figure 1).

Two affected individuals (III-1, IV-4) and one unaffected (IV-5) were sequenced by whole genome sequencing (WGS). Variant annotation and filtering yielded a single heterozygous variant in EPHA2 (chr1p36), NM_004431.4: c.2826-9G>A, 9 base pairs from the acceptor splice site into the $16^{\text {th }}$ intron of the gene. This variant was classified as affecting splicing by dbscSNV v.1.1 (11).

Direct sequencing confirmed a single base substitution (c.2826-9G $>A$; p.D942fsXC71) in intron 16 of EPHA2 that cosegregated with all affected members 
of the family (Figure 2). This single base substitution has been reported by Zhang et al (14) and is predicted to create a novel splice acceptor site in the intronic sequence causing an extra $7 \mathrm{bp}$ to be included in the processed transcript. It is predicted to result in a frame-shift in codon 942 and likely produce an aberrant protein with an additional 71 amino acid residues. The sequence variant is located in the SAM domain of EPHA2. The structural prediction of the SAM domain for this protein shows that the structure of the mutant protein is considerably different than that the wild type protein (Figure 3). The identified variant was not seen in 200 healthy individuals from the European population. We also screened EPHA2 in our entire ADCC panel ( $n=96)$; no other likely disease-causing variants were found.

Haplotype analysis was undertaken using five microsatellite markers D1S2697, D1S436, D1S1592, D1S2826 and D1S2644 from the 1p36.1 region spanning $6.67 \mathrm{Mb}$ encompassing EPHA2 in order to compare with the previously published Australian families carrying the same mutation $(14,15)$. Recombinant chromosomes were identified with the markers D1S2697 in unaffected individuals II-4, and III-2 and III-9; D1S436 in only one unaffected III-9; D1S1592 in 2 unaffected members II-2 and III-9; D1S2826 was completely uninformative and finally D1S2644 in three unaffected members II-4, III-2 and III-9. The Individuals III2 and III9 did not carry the mutation despite carrying the disease haplotype of the microsatellite markers (Figure 1). The EPHA2 gene resides between markers D1S436-0.58Mb- EPHA2 -1.6MbD1S1592. We covered this region with all available markers on the Marshfield list to further narrow down the distance between these two markers harbouring the gene, which basically appeared to be very tightly linked. Whole genome mapping also missed this locus and showed significant lod score 2.9 on two different loci 10q11.23 with SNP_1725084 and 10q21.1 with SNP_1720615 respectively. Further, microsatellite markers were used to check these regions on chromosome $10 q$ and were excluded (data not shown). The haplotype alleles were different than in the previously published three Australian families, suggesting that this recurrent mutation was an independent event and resulted in a different phenotype. 


\section{Discussion}

Here we report a recurrent splice-site mutation c.2826-9G>A in EPH receptor A2 (EPHA2) on chromosome $1 \mathrm{p} 36.1(12,13)$ caused an isolated posterior nuclear cataract (PNC) in a four generation English family. This recurrent mutation has been identified to cause posterior nuclear cataract for the first time and further emphasises the heterogeneity associated with congenital cataract. Previously, the same mutation has been reported in three Australian families causing total congenital cataract (14, 15).

Bilateral posterior nuclear cataract (PNC) is a clinically distinct phenotype. Opacities were seen in the embryonic and fetal nucleus along with the posterior pole of the lens in all the affected family members. EPHA2 thereby plays a significant role in lens development and transparency, having been shown to be highly expressed in epithelial cells and fiber cells, with an EPHA2 knock-out mice resulting in progressive cortical cataract in mice (16).

EPHA2 comprises 17 exons, encoding a transmembrane protein of 976 amino acids with an extracellular amino-terminal and cytoplasmic carboxy-terminal. The extracellular region comprises a conserved Eph-ligand binding domain, a cysteinerich domain, two fibronectin type-III repeats, a transmembrane segment, a juxtamembrane region, a tyrosine kinase, a cytoplasmic sterile- $\alpha-m o t i f(S A M)$ and PDZ domain in the cytoplasmic region (17). The SAM domain of the protein shows majority of the cataract causing mutations.

So far, 8 different autosomal dominant pathogenic mutations have been reported in EPHA2; one American family, three Australian families, one British and three Chinese families, whereas an autosomal recessive mutation was reported in a Pakistani family with a nuclear cataract $(14,15,18,19)$. Recently, Bu et al identified a novel splice donor site mutation c. $2825+1 \mathrm{G}>\mathrm{A}$ in a Chinese family with autosomal dominant nuclear cataract (20) (Summarised in Table 2). In the population of SouthEast Australia, approximately $5 \%$ of inherited cataracts are caused by the pathogenic mutations occuring in EPHA2 gene (15). 
Eph receptors represent the largest family of receptor tyrosine kinases and are divided into EphA receptors and EphB receptors (9 EPHAs and 5 EPHBs), preferentially binding to type $A$ and type $B$ ephrins respectively (5 EFNAs and 3 EFNBs). The Eph family is capable of bidirectional signaling upon interaction between receptor-ligand pair (17). Eph-ephrin ligands play a major role in morphogenesis and in numerous developmental processes along with lens homeostasis $(21,22,23)$. It has been shown that ephrin-A5 acts as a regulator for $E P H A 2$, as loss of ephrin-A5 function can lead to progressive cataract in mice, thus describing the significance of EPHA2 signalling in maintaining lens transparency and architecture. Further studies have shown that the intraction of ephrin-A5 with EPHA2 receptor regulates the adherens junction complex; this is caused by enhanced recruitment of $\beta$-catenin to $\mathrm{N}$-cadherin (24).

As most of the pathogenic mutations were found in the SAM domain, Park et al have investigated the effect of SAM domain mutations on EPHA2 activity. These mutations cogently destabilised the transiently expressed mutant proteins, impaired cell migration, reduced to half-life, and underwent degradation through the proteasomal pathway. These mutations did not show any effect on receptor activation, but caused a reduction in phosphorylation of Akt, a downstream effector molecule in EPHA2 signaling $(25,26)$. Recently Dave et al have further investigated the effects of two mutations, p.T940I and p.D942fsXC71 (as identified in our study), located within the SAM domain. These mutations resulted in protein mis-localization to the perinuclear space and co-localized with the cis-Golgi apparatus which indicated the sub-organellar/cellular retention of the mutant proteins. Mis-localization of these mutant proteins in epithelial cells suggested that some pathogenic mutations in EPHA2 probably affect lens epithelial cell homeostasis and plays a significant role in catarctogenesis.

Two studies have shown the deleterious effect of p.D942fsXC71; leading to total cataract in three Australian families $(14,15)$ Here we have found the recurrent p.D942fsXC71 in a British family with a different phenotype, posterior nuclear cataract. These results show further heterogeneity in inherited cataract, with the same mutation, on a different genetic background, causing a different phenotype, presumably through diverse mechanisms. 


\section{Acknowledgments}

Funding/ Support: Supported by grants from the National Institute for Health Research Biomedical Research Centre at Moorfields Eye Hospital National Health Service Foundation Trust and UCL Institute of Ophthalmology (UK), Moorfields Eye Hospital Special Trustees (UK), Moorfields Eye Charity (UK), and the Foundation Fighting Blindness (USA). Michel Michaelides is supported by an FFB Career Development Award.

We would like to thank the members of the family for taking part in this study.

\section{References}

1. Gilbert C, Foster A. Childhood blindness in the context of VISION 2020-the right to sight. Bull World Health Organ 2001; 79:227-32. [PubMed]

2. Rahi JS, Dezateux C. Measuring and interpreting the incidence of congenital ocular anomalies: lessons from a national study of congenital cataract in the UK. Invest Ophthalmol Vis Sci 2001; 42:1444-1448. [PubMed]

3. Reddy MA, Francis PA, Berry V, Bhattacharya SS, Moore AT. Molecular genetic basis of inherited cataract and associated phenotypes. Surv Ophthalmol 2004; 49:300-315. [PubMed]

4. Krumpaszky HG, Klauss V: Epidemiology of blindness and eye disease. Ophthalmologica 1996; 210: 1-84.[PubMed]

5. Churchill A and Graw. J Clinical and experimental advances in congenital and paediatric cataracts Phil. Trans. R. Soc. B 2011; 366: 1234-1249. [PubMed]

6. Ionides A, Francis P, Berry V, Mackay D, Bhattacharya SS, Shiels A, Moore AT. Clinical and genetic heterogeneity in autosomal dominant congenital cataract. Br J Ophthalmol. 1999; 83:802-8. [PubMed] 
7. Francis PJ, Berry V, Bhattacharya SS, Moore AT: The genetics of childhood cataract. J Med Genet 2000a; 37: 481-488. [Pub Med]

8. Shiels A, Bennett TM, Hejtmancik JF. Cat-Map: putting cataract on the map. Mol Vis 2010; 16:2007-15. [PubMed].

9. Berry V, Gregory-Evans C, Emmett W Waseem N, Raby J, Prescott D, Moore AT, and Bhattacharya SS. Wolfram Gene (WFS1) Mutation Causes Autosomal Dominant Congenital Nuclear Cataract in Humans; 2013;21(12):1356-60. [PubMed]

10.Shiels A, Bennett TM, Knopf HL, Maraini G, Li A, Jiao X and Hejtmancik JF. The EPHA2 gene is associated with cataracts linked to chromosome 1p. Mol Vis; 2008 14: 2042-2055. [PubMed]

11. Xueqiu J, Boerwinkle E, and Liu X. "In Silico Prediction of SpliceAltering Single Nucleotide Variants in the Human Genome." Nucleic Acids Research 2014; 42(22):13534-44. [PubMed]

12. Ionides AC, Berry V, Mackay DS, Moore AT, Bhattacharya SS, Shiels A. A locus for autosomal dominant posteriorpolar cataract on chromosome 1p. Hum Mol Genet 1997; 6:47-51. [PubMed]

13. McKay JD, Patterson B, Craig JE, Russell-Eggitt IM, Wirth MG, et al. The telomere of human chromosome $1 \mathrm{p}$ contains at least two independent autosomal dominant congenital cataract genes. $\mathrm{Br} \mathrm{J}$ Ophthalmol 2005; 89: 831-834. [PubMed]

14.Zhang T, Hua R, Xiao W, Burdon KP, Bhattacharya SS, CraigJE, Shang D, Zhao X, Mackey DA, Moore AT, Luo Y, Zhang J, Zhang X. Mutations of the EPHA2 receptor tyrosine kinase gene cause autosomal dominant congenital cataract. Hum Mutat 2009; 30:E60311. [PubMed].

15. Dave A, Laurie K, Staffieri SE, Taranath D, Mackey DA, Mitchell P, Wang JJ, Craig JE, Burdon KP, Sharma S. Muta- tions in the EPHA2 gene are a major contributor to inherited cataracts in South-Eastern Australia. PLoS One 2013; 8:e72518-[PubMed]

16. Jun G, Guo H, Klein BE, Klein R, Wang JJ, et al. EPHA2 is associated with age-related cortical cataract in mice and humans. PLoS Genet 2009; 5: e1000584. [PubMed] 
17. Pasquale EB. Eph receptors and ephrins in cancer: bidirectional signalling and beyond. Nat Rev Cancer 2010; 10:165- 80. [PubMed]

18. Kaul H, Riazuddin SA, Shahid M, Kousar S, Butt NH, et al. Autosomal recessive congenital cataract linked to EPHA2 in a consanguineous Pakistani family. Mol Vis 2010; 16: 511-517. [PubMed]

19. Shentu XC, Zhao SJ, Zhang L, Miao Q. A novel p.R890C mutation in EPHA2 gene associated with progressive childhood posterior cataract in a Chinese family. Int J Ophthalmol 2013;6: 34-38. [PubMed]

20. Bu J, He S, Wang L, Li J, Liu J, Zhang X. A novel splice donor site mutation in EPHA2 caused congenital cataract in a Chinese family. Indian J Ophthalmol. 2016; 64(5):364-8. [PubMed]

21. Pasquale EB. 2005. Eph receptor signalling casts a wide net on cell behaviour. Nat Rev Mol Cell Biol 2005; 6:462-475. [PubMed]

22. Lackmann M, Boyd AW. Eph, a protein family coming of age: more confusion, insight, or complexity? Sci Signal 2008; 1(15):re2. [PubMed]

23. Pasquale EB. Eph-ephrin bidirectional signaling in physiology and disease. Cell 2008; 133:38-52. [PubMed]

24. Cooper MA, Son Al, Komlos D, Sun Y, Kleiman NJ, Zhou R. (2008) Loss of ephrin-A5 function disrupts lens fiber cell packing and leads to cataract. Proc Natl Acad Sci U S A 2008; 105: 16620-16625. [PubMed]

25. Park JE, Son Al, Hua R, Wang L, Zhang X, Zhou R. Human Cataract Mutations in EPHA2 SAM Domain Alter Receptor Stability and Function.PLoS One 2012; 7: e36564. [PubMed]

26. Park JE, Son AI, Zhou R. Roles of EPHA2 in Development and Disease Genes 2013; 4:334-357. [PubMed]

27. Dave A, Martin S, Kumar R,. Craig JE, Burdon KP, Sharma S. EPHA2 mutations contribute to congenital cataract through diverse mechanisms. Molecular Vision 2016; 22:18-30 [PubMed] 


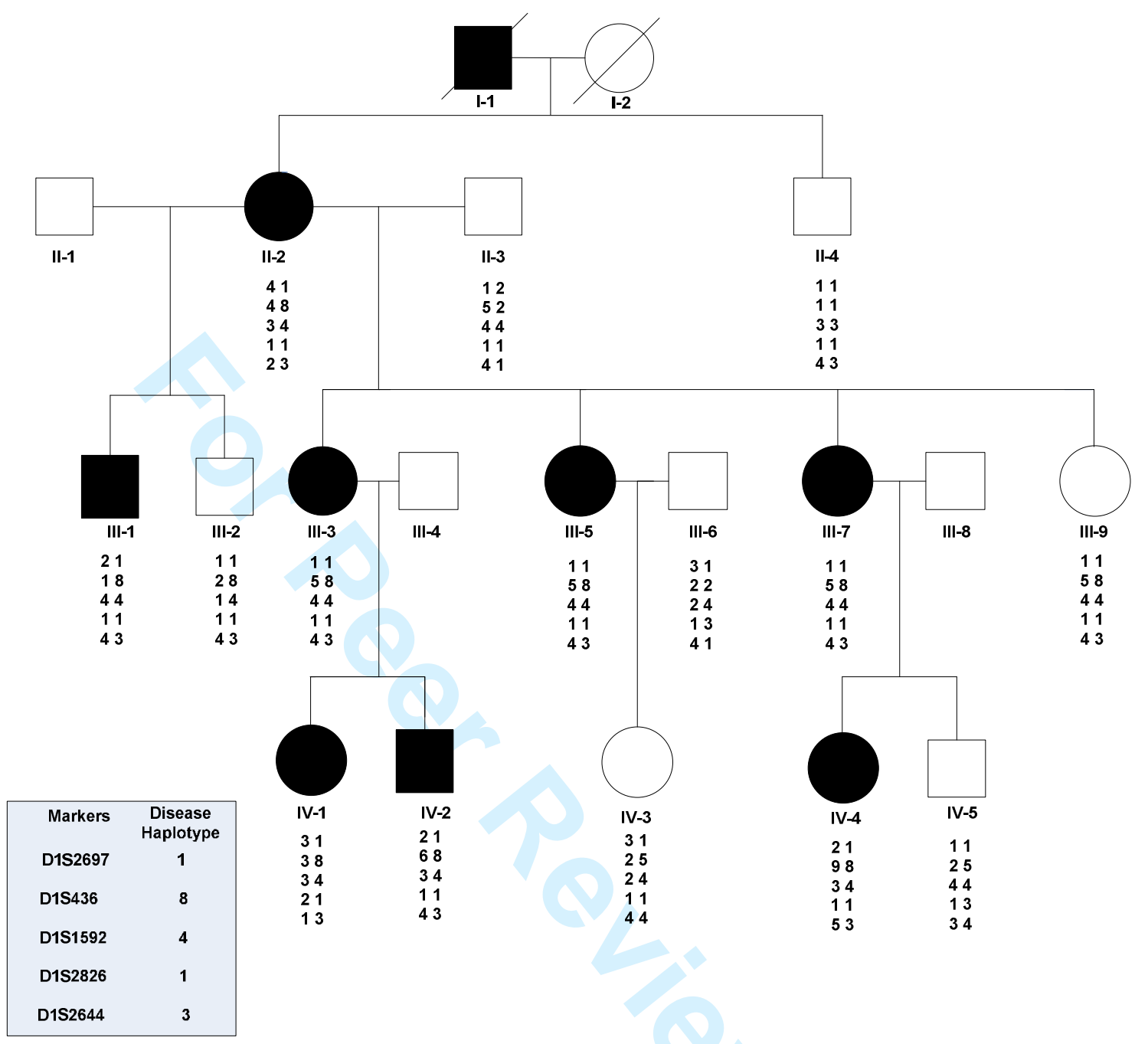

Figure-1: Abridged pedigree of the posterior nuclear cataract family in this study showing the segregation of five chromosome $1 p$ markers encompassing EPHA2 gene listed in descending order. Squares and circles symbolize males and females respectively. Open and filled symbols indicate unaffected and affected individuals. Markers and the disease haplotype is shown in the box. 


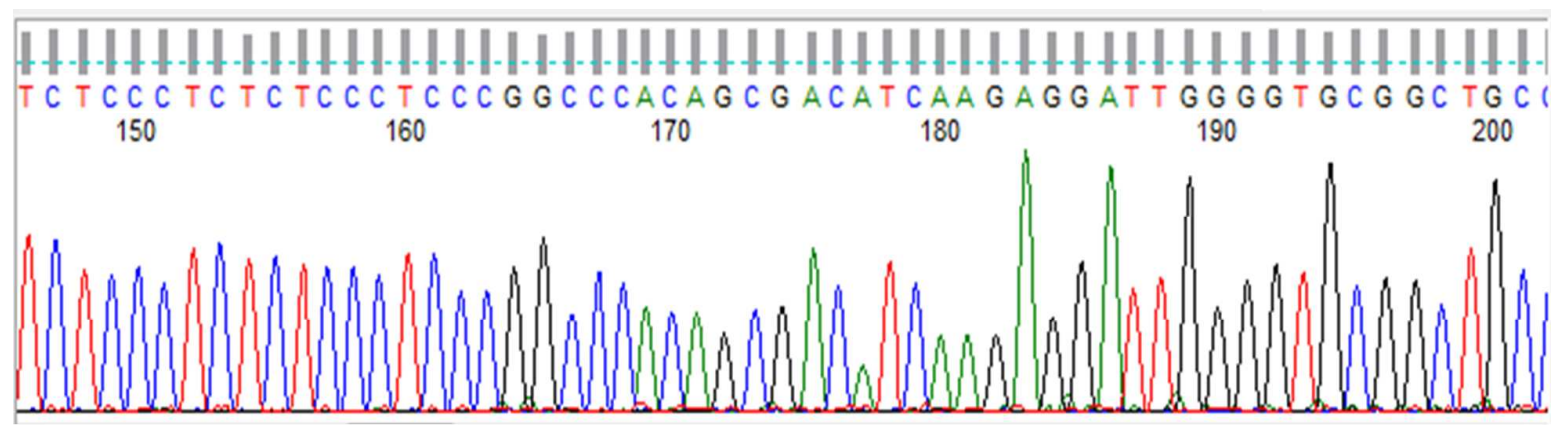

Unaffected individual

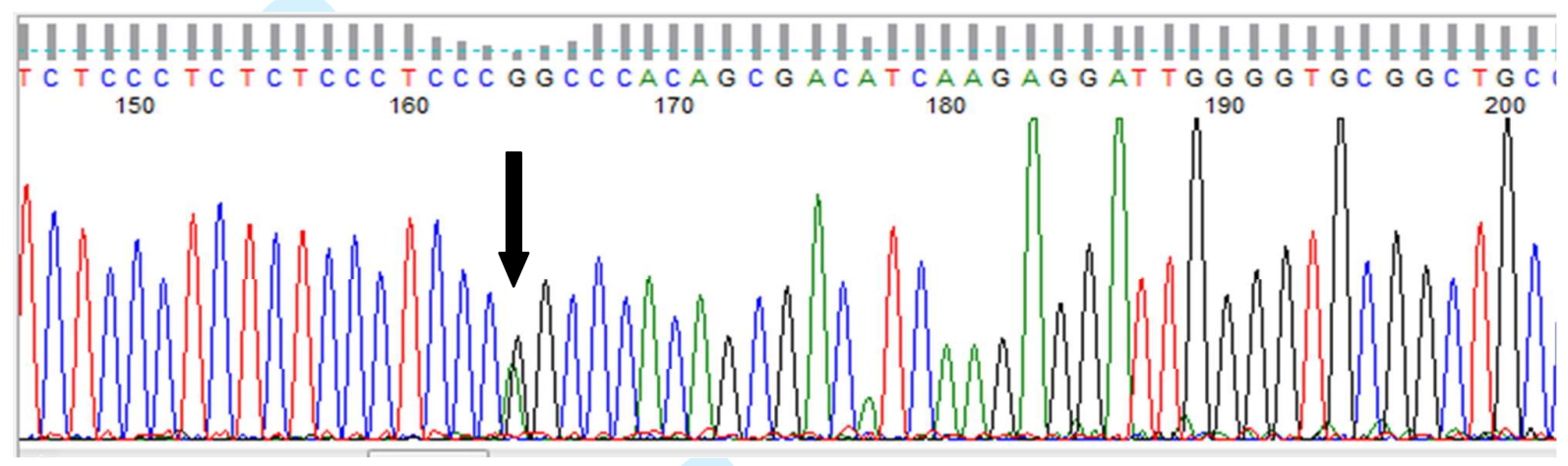

Affected individual

Figure 2: Sequence analysis of EPHA2 gene with an unaffected individual (upper chromatogram) illustrates a normal control and a splice-site mutation c.2826-9G >A shown in an affected individual with posterior nuclear cataract.

URL: http://mc.manuscriptcentral.com/nopg E-mail: ophthalmicgenetics@yahoo.com 


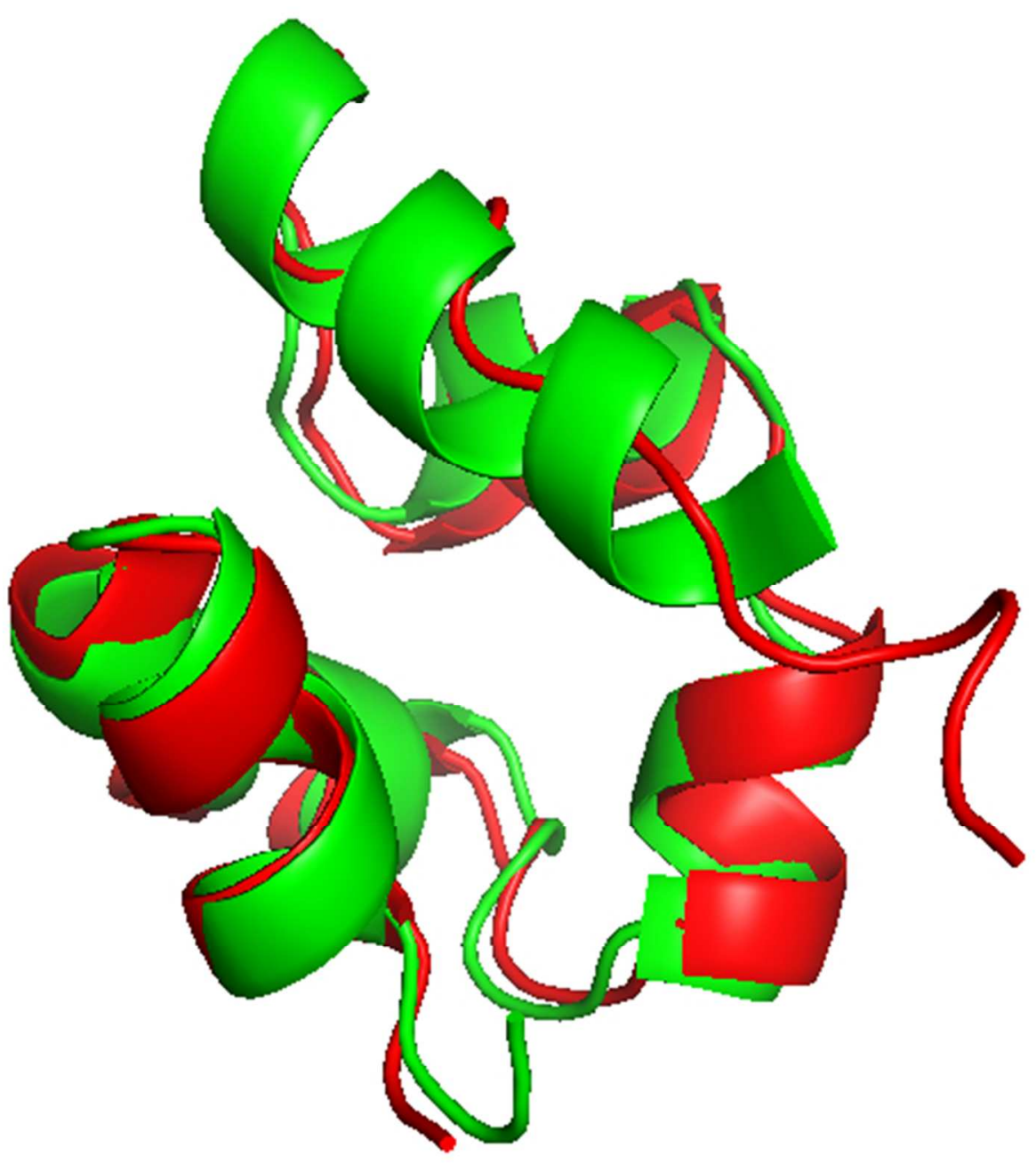

Figure 3: The predicted structure of the SAM domain of the mutant EPHA2 protein (red) shows considerable differences with that of the wild type protein (green). 
Table 1. PRIMERS FOR EPHA2

\begin{tabular}{|l|l|l|c|c|}
\hline Set & Forward primer & Reverse primer & $\begin{array}{c}\text { Annealing } \\
\text { temp }{ }^{\circ} \mathrm{C}\end{array}$ & $\begin{array}{c}\text { Product } \\
\text { size(bp) }\end{array}$ \\
\hline Exon1 & gacgctcaaactttggaagg & ttattctccggagcccctat & 60 & 614 \\
Exon2 & cgagggatgattttcttgga & ctgggcctcagtttctccat & 60 & 305 \\
Exon3a & tcagccacttatggatgcag & AAGGCCAGGTAGAAGCCTTT & 60 & 559 \\
Exon3b & ACGTGACTGCAACAGCTTCC & gcagggatgagcttaccaag & 60 & 616 \\
Exon4 & ttgccgatgagaaaacaggt & GCAGGTGACGCTGTAGACAA & 60 & 506 \\
Exon5 & CTCCTGCGAGTGTGAGGAA & acttgctctgctgcctctct & 60 & 596 \\
Exon6 & tgagcacaggagttcaaagc & gctgccttgggagatgtaac & 60 & 481 \\
Exon7 & gagtcctggctcatgcattt & tgattcacttcctttcccaag & 60 & 439 \\
Exon8 & cccacatacctgcaatacc & cgtatatcctcgcaccatcc & 60 & 447 \\
Exon9 & cctcctaggaccaaagtaggg & gagacttggaccaggctgtg & 60 & 311 \\
Exon10 & TCTCCAAGTCAGgtgagacg & AGCATGCCCTTGTACACCTC & 60 & 534 \\
Exon11 & CATCCATCCTGTGTCACTCG & Caggtattggggagaagtgg & 60 & 496 \\
Exon12-13 & Cacacctctccccatacctg & Aggaccattgcagccaag & 60 & 687 \\
Exon14 & Ccctgcatggtgtcctct & Tggagcaagcctaagaaggt & 60 & 419 \\
Exon15 & Ggtggcagctcaagaaagg & Ggccatcgtgtccagtctaa & 60 & 496 \\
Exon16 & Tggaggggcagcagtagtta & Attgaggggcagggaaga & 60 & 462 \\
Exon17 & ttctaggctgtggctccttc & TCCCTGGTCATCTCCTCAGT & 60 & 487 \\
\end{tabular}


Table 2: Spectrum of mutations in the EPHA2 gene leading to Congenital Cataract

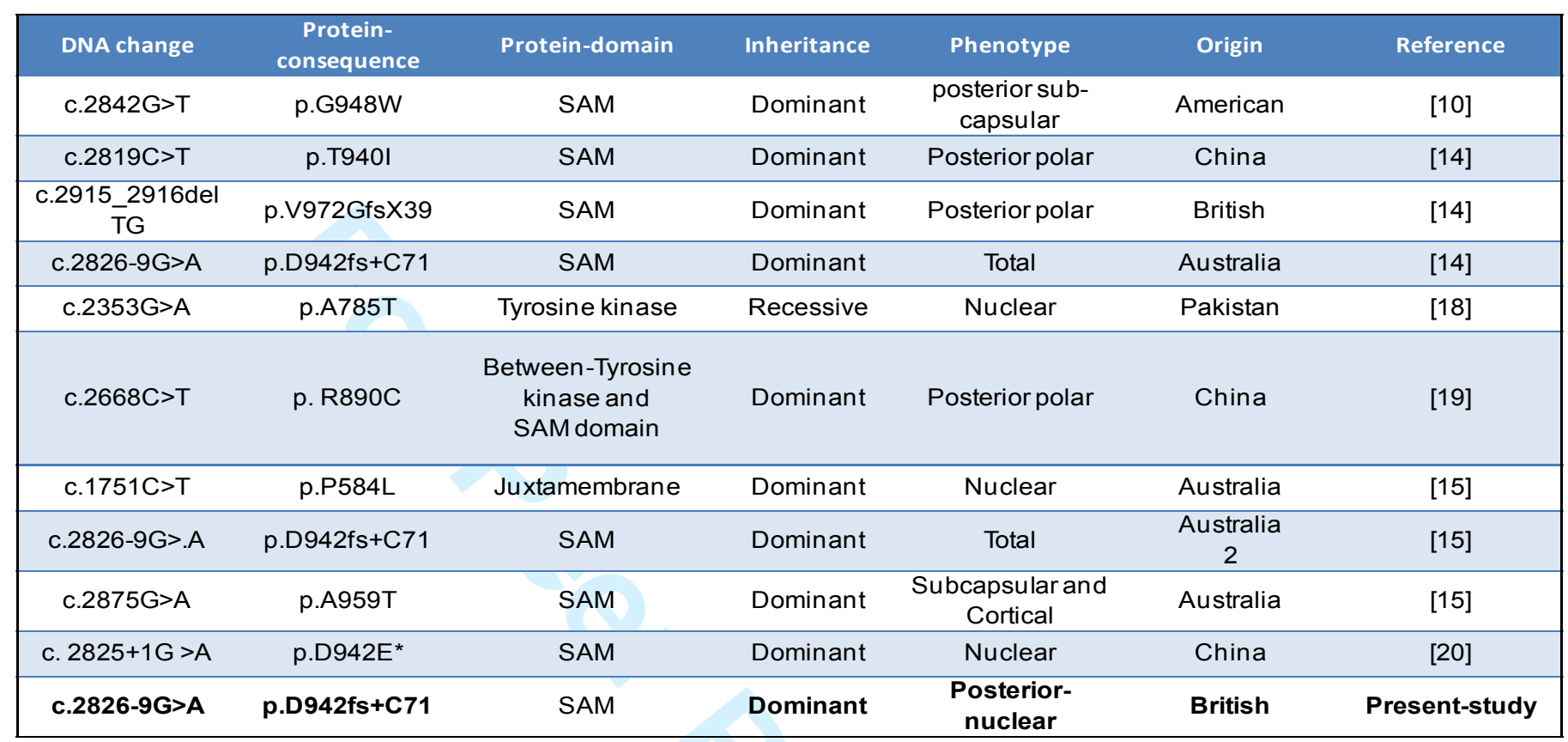

